\title{
Ser migrante: implicações territoriais e existenciais da migração*
}

\author{
Eduardo Marandola Jr.** \\ Priscila Marchiori Dal Gallo***
}

\begin{abstract}
Migração e mobilidade são fenômenos constituintes da experiência contemporânea. Estar no mundo, hoje, é conviver com a mobilidade e a migração, e todas suas implicações. Do ponto de vista existencial, esta é uma experiência desconcertante, em que as referências espaciais e socioculturais são reconstituídas, num processo que envolve e atinge o próprio cerne da autoidentidade: a segurança existencial. Partimos da pergunta "que é ser migrante?" para refletir sobre as implicações existenciais e territoriais da migração, procurando entendê-la enquanto um fenômeno vivido em diferentes escalas espaço-temporais, mas que possui, do ponto de vista fenomenológico, uma mesma essência constitutiva. Esse percurso leva a um pensar ontológico acerca das estratégias e consequências do fenômeno migratório, o que faz refletir sobre o papel da identidade territorial, do envolvimento com o lugar e das redes sociais no movimento de sair do lugar de origem e estabelecer-se no local de destino.
\end{abstract}

Palavras-chave: Mobilidade. Lugar. Segurança existencial. Fenomenologia da migração. Geografia da população.

\section{Introdução}

Que é ser migrante? Esta pergunta expressa a preocupação em pensar o fenômeno migração na forma como este é vivido. Em termos fenomenológicos, a atenção recai sobre a forma como o fenômeno aparece na experiência. Essa pergunta expressa também uma preocupação ontológica original: o migrante é um ser deslocado, movido de seu lugar primevo. E é neste deslocamento que procuramos o significado do que é esta condição.
A tradição dos estudos migratórios consolidou uma série de questões fundamentais que giraram em torno das leis da migração (RAVEINSTEIN, 1980) e dos motivos e forças sociais que atraem ou expulsam as populações, enquanto reflexos da própria estruturação produtiva do capital e de suas necessidades. Neste sentido, os movimentos se davam por classes, não por indivíduos que decidiam isoladamente migrar (SINGER, 1973). Versões clássicas, estruturalistas ou pós-estruturalistas elaboraram estas e

\footnotetext{
* Uma versão preliminar deste texto foi apresentada no VI Encontro Nacional de Migrações, realizado de 12 a 14 de agosto de 2009, em Belo Horizonte, Minas Gerais. Agradecemos as leituras críticas e o incentivo de Fernanda Cristina de Paula, Ricardo Ojima e, especialmente, Daniel Joseph Hogan.

** Geógrafo, pesquisador colaborador do Núcleo de Estudos de População - Nepo, da Universidade Estadual de Campinas - Unicamp.

*** Bolsista PIBIC/CNPq, Núcleo de Estudos de População - Nepo, da Universidade Estadual de Campinas - Unicamp.
} 
outras perspectivas para explicar a lógica dos processos de redistribuição espacial da população e suas diferentes consequências.

No entanto, apesar destas bases comuns, enquanto fenômeno complexo e multifacetado, a migração é estudada no contexto dos estudos populacionais, recebendo a confluência de abordagens e disciplinas que, cada qual com suas preocupações e objetos, compõem um grande quadro sobre o migrante, seus movimentos, os processos materiais, as consequências e implicações em diferentes escalas, os simbolismos e as transformações culturais. Conforme mostram Brettell e Hollifield (2008), cada disciplina possui sua questão de pesquisa, os níveis ou unidades de análise, teorias dominantes e hipóteses orientadoras das investigações.

A intensificação dos fluxos migratórios no período pós-1990, com a crescente mobilidade planetária e novos desenvolvimentos na área de transportes e comunicação, no entanto, tem produzido reflexos diretos nos estudos e teorias migratórias (FAVELL, 2008). A velocidade, intensidade e diversidade contemporâneas dificultam muito a apreensão dos fluxos e das dinâmicas que têm ritmos espaço-temporais muito variados, além de uma diversidade nunca vista. Diferente da modernidade sólida, para usar uma expressão de Bauman (2001), na modernidade líquida a fluidez é a tônica das instituições, relações sociais, mercado e até da esfera cotidiana. Isso deixa os cientistas sempre num terreno pantanoso no que se refere à apreensão da realidade e seu estudo.

Esse cenário produziu pelo menos dois rebatimentos em termos das tendências dos grandes paradigmas científicos: a ênfase nos processos identitários, da esfera do cotidiano e dos microprocessos; e a atenção à dimensão espacial dos fenômenos (SANTOS, 2000; MASSEY, 2008). Nos estudos migratórios, observam-se alterações nas tradicionais abordagens explicativas das migrações (estruturalistas), com fortalecimento da atenção na identidade e nos elementos simbólicos do processo (AHMED, 1999; PADILLA, 2009). Por outro lado, a dimensão territorial das migrações tem ganhado importância, tanto em termos dos territórios migrantes quanto dos estudos de lugares e espaços específicos diante do fenômeno migratório (RAFFESTIN, 2003; SAQUET, 2007).

No entanto, a maior parte desta bibliografia enfoca o tema pelo viés sociocultural, dos grupos e de suas práticas, não estando direcionada para as questões propriamente existenciais destas transformações. Por outro lado, a dimensão espacial, via território, continua sendo entendida, sobretudo, como metáfora, ou por um viés materialista, que limita o território às relações de poder estabelecidas por forças econômicas ou políticas.

A Geografia é a disciplina em que estas abordagens estão potencialmente conciliadas. Ela é mais do que o estudo de padrões espaciais da migração, envolvendo uma gama de processos e fenômenos constituintes dos lugares, das redes e dos fluxos (HARDWICK, 2008). Favell (2008) chama atenção para o potencial da análise contemporânea da Geografia, que considera o lugar enquanto dotado de significado e dinâmica cultural, permitindo um olhar para as dinâmicas próprias do e no espaço, ontologicamente integrante da população que ali vive. Para avançar nesse sentido, é necessário trilhar esta reflexão ontológica de fundo, superando a dissociação moderna espaçosociedade, em busca de uma abordagem eminentemente existencial-fenomenológica.

No contexto dos estudos migratórios, a dimensão existencial está parcialmente contemplada pelos trabalhos historiográficos, que tomam a migração enquanto narrativa e memória (DINER, 2008). Com seus estudos clássicos sobre a condição do estrangeiro e sua adaptação, Georg Simmel (1983; 1994) foi pioneiro em trazer a dimensão individual para uma análise social dos processos ligados à migração e à própria sociedade. Outras disciplinas que contribuem para este olhar são a Psicanálise e a Psicologia, que buscam compreender os impactos do processo migratório para a identidade e a personalidade (VIANA, 1978; DeBIAGGI; PAIVA, 2004; OLIVEIRA, 2005; FUKS, 2005).

Como uma mobilidade em si, a migração é um fenômeno que envolve tanto a materialidade quanto a produção social e 
a corporeidade, necessitando destes três polos para ser compreendido (CRESSWELL, 2006; KELLERMAN, 2006). Estas dimensões têm sido exploradas de maneiras diferentes, mas nunca enfrentadas de forma direta pelos estudos migratórios ao mesmo tempo. A dimensão territorial tem sido vista como organização espacial ou como a dimensão legal das migrações internacionais (sempre com um viés materialista do território), enquanto a dimensão existencial tem aparecido em estudos antropológicos, históricos, psicossociais ou psicanalíticos. Mas a dimensão propriamente geográfica dos processos de territorialização e desterritorialização só tem sido abordada muito recentemente, e não necessariamente numa perspectiva existencial.

$\mathrm{O}$ contexto em que tais estudos têm florescido é o das discussões contemporâneas sobre a modernidade líquida, os novos nomadismos e as redefinições das identidades territoriais. Cresceu nos últimos dez anos a fileira dos geógrafos dedicados a tirar a dimensão territorial de simples metáfora para chão ou solo, perspectiva que proliferava em toda a bibliografia sobre hibridismos, transculturalismo, mudanças culturais e globalização (BADIE, 1996; HALL, 2003; 2009). Alguns autores, como Mesquita (1995), Haesbaert (2004; 2008), Saquet (2007; 2009) e Raffestin (2003, 2009), têm se dedicado de forma mais sistemática a esta discussão, com suas respectivas abordagens e preocupações de fundo. Destaque especial merece Jöel Bonnemaison (BONNEMAISON; CAMBRÉZY, 1996; BONNEMAISON, 2002[1981]; 2005), que, em seus estudos tropicalistas, foi um dos primeiros a pensar o território em sua dimensão cultural, chegando a considerar o território, junto com o lugar, como um paradigma para a nova geografia cultural em desenvolvimento nos anos 1990.

Nosso ponto de partida, no entanto, é diferente do deles, embora corra em paralelo. Se os autores se concentram em compreender as implicações para os grupos, nosso enfoque se direciona para existência e, a partir dela, podemos pensar os grupos. É na experiência da migração que buscamos compreender que é ser migrante. Assim, migrar é sair do seu lugar, envolvendo pro- cessos de redefinições das territorialidades, que não são necessariamente sucessivos nem ordenados. Que significa, para a constituição da identidade e do eu, o rompimento da ligação original ser-lugar natal? Em termos ontológicos, há um abalo na segurança existencial e na identidade territorial que precisa ser compreendido como elemento central do processo migratório.

Este texto é uma aproximação ao tema, um convite à sua discussão e suas implicações para pensar as migrações e os migrantes na contemporaneidade na área dos estudos populacionais. Exploraremos alguns elementos que ligam ser-lugar enquanto relação fenomenológica originária, buscando, a partir desta perspectiva, compreender as implicações territoriais e existenciais da migração, pesando o papel dos grupos e coletividades, mas focando as repercussões tais como são experiencialmente vividas.

\section{Migrar: desestabilização ser-lugar}

Se a pergunta que guia o texto é "que é ser migrante?" e a busca por sua resposta está na territorialidade e na existência, dois termos são centrais para esta construção: lugar e ser. Mais importante ainda, a essência fenomênica ser-lugar é central para se pensar em termos ontológicos a questão em tela.

Casey (2001) afirma que não há lugar sem homem, nem homem sem lugar. Esta afirmação revela a compreensão ontológica da espacialidade a partir da qual existe a indissociabilidade ser-lugar, homem-espaço. Somos nossos lugares, assim como eles nos são. Não estamos no espaço: somos sendo espacialmente (HEIDEGGER, 2001a).

A filosofia fenomenológica vem contribuindo de forma notável nos últimos anos para esta compreensão cada vez mais precisa e ao mesmo tempo ampla da espacialidade do ser. Uma longa tradição de pensamento sustenta esta perspectiva, desde os gregos, embora as bases mais sólidas tenham se consolidado a partir da fenomenologia do século XX, principalmente com Heidegger e Bachelard (BOLLNOW, 2008). O primeiro deles é especialmente im- 
portante neste sentido, já que, perseguindo a questão ontológica fundamental, erigiu um conjunto de reflexões que colocam o lugar e o espaço como centrais para pensar a existência (MALPAS, 2008; SARAMAGO, 2008).

Nessa perspectiva, a dimensão territorial refere-se à própria constituição do ser, enquanto área de controle (mesmo que simbólico) que permite a continuação da existência, fornecendo a chamada segurança ontológica (GIDDENS, 2002). É esta segurança que permite ao ser continuar sendo, ou seja, manter-se vigente, existindo no mundo (HEIDEGGER, 2001b).

Sack (1997) aborda a dimensão existencial da relação com o lugar a partir do self (eu), entendendo a relação self-lugar como uma teia indissociável de mútua constituição. Para ele, ambos estão no centro de constituição da pessoa e do espaço, sendo o ponto no qual os fenômenos e dinâmicas de outras esferas se embatem na realidade geográfica. Segundo o autor, o self é composto pela natureza, pelos significados e pelas relações sociais, tanto quanto o lugar, e é por isso que ambos apresentam personalidades específicas em cada tempo.

O processo de desenraizamento original iniciado pelo movimento migratório se dá, em termos existenciais, pela alteração da territorialidade consolidada, a modificação desta relação originária self-lugar, saindo do lugar-natal, o que implica deixar os lugares de infância, juventude ou idade adulta, responsáveis pela nossa formação enquanto pessoa e sobre os quais está edificada nossa identidade. Implica, portanto, sair dos territórios da segurança e lançar-se no mundo, em lugares de pouca ou nenhuma familiaridade, onde há pouco ou nenhum controle, uma das raízes da insegurança (MARANDOLA Jr., 2008a).

A bibliografia clínica e antropológica elenca um razoável número de estresses e lutos causados pela experiência migratória, relacionados às várias perdas, desorientações e incertezas consequentes da mudança. O local de destino representa uma nova realidade para o migrante em termos tanto culturais quanto espaciais. A bibliografia clássica indica alguns dos processos que ocorrem neste devir, tais como a integração, a assimilação, a separação ou a marginalização (BERRY; POORTINGA, 2002), constituindo o processo mais geral de adaptação do migrante, que envolve não apenas questões comportamentais e culturais (HOGAN, 1974), mas também adaptações do seu próprio modo de ser. Como a adaptação nem sempre é possível (nem sempre a pessoa tem condições mentais de realizá-la), o desgaste emocional pode se avolumar a ponto de gerar a chamada Síndrome do Migrante, ou Síndrome de Ulisses (PASQUA; MOLIN, 2009).

A expressão antropológica deste processo é o embate entre migrantes e estabelecidos, problemática clássica de todos os estudos sobre alteridade, adaptação cultural e migração (insiders e outsiders) (ELIAS, 1994). O outro é o desconhecido, que ameaça o eu e sua pureza, provocando o medo e a repulsa e, não raro, reações hostis que podem gerar estigmatização (GOFFMAN, 1982; BAUMAN, 1998). Esta oposição revela não apenas a diferença de pertença e identidade entre grupos, mas também uma diferenciação de apropriação dos saberes do lugar e de sua inserção territorial (MARANDOLA Jr., 2008b).

Elsa Lechner aborda a questão pelo ângulo da psiquiatria, identificando no processo migratório elementos potenciais que atingem a saúde mental. Segundo a autora, a experiência migratória é a da descontinuidade e ruptura, alterando a trajetória pessoal e rompendo laços. "Laços esses que também são inscritos no corpo, cinestésicos e vivenciados. Esta experiência provoca um deslocamento do sentimento de si que pode concorrer para o mal-estar existencial ou mesmo para a doença." Ela corrobora a importância da dimensão territorial do processo, afirmando que na migração "as identidades são inter-territoriais e o sentimento de pertença quase extra-territorial, desafiando formas convencionais de representação das identidades" (LECHNER, 2007, p. 81). Migrar é ser obrigado a desenvolver outros tipos de territorialidade, dando um salto em direção ao desconhecido.

É por isso que a desestabilização da ligação essencial ser-lugar causa um abalo na segurança existencial e identidade terri- 
torial do migrante, que tem de enfrentar um desencaixe espacial. Isso o torna suscetível à angústia e ansiedade, impondo a necessidade de enraizar-se no lugar de destino, ou de manter os vínculos com o lugar natal, apesar de ter migrado. A segurança existencial e a identidade dependem de a pessoa estabelecer e cultivar laços com o lugar, envolvendo-se com ele (MARANDOLA Jr., 2008c).

Lussi e Marinuci (2007) e Lussi (2009) procuram sistematizar os elementos e situações que tornam a condição migrante vulnerável, entre os quais se destacam as questões legal, religiosa, familiar, econômica e simbólica. Todos os aspectos arrolados pelos autores estão associados ao envolvimento com o lugar, à identidade e ao processo de territorialização incipiente no lugar de destino.

Nesse sentido, o migrante sente a necessidade de fixar-se para poder alcançar uma sensação de bem-estar, aliviando o incômodo sentimento de incerteza e instabilidade que perdura e se reforça com a ausência do lugar. No entanto, a fixação do migrante no local de destino tem algumas restrições ou condições em termos de identificação sociocultural e espacial. O envolvimento de um indivíduo com o lugar é um processo complexo que não ocorre aleatoriamente. Alguns fatores encorajam/ incentivam esse envolvimento, enquanto outros repelem qualquer tentativa ou interesse em fazê-lo.

Entre os fatores de encorajamento, a identificação com o lugar é crucial. O estabelecimento de laços e a sensação de pertencimento ocorrem em um lugar cujas características sociais, culturais e a organização espacial não sejam de todo desconhecidas. É o chamado place attachment (envolvimento com o lugar), que é um dos aspectos dos efeitos de lugar, ou senso de lugar (LOW; ALTMAN, 1992). Para a psicologia ambiental, o processo de envolvimento com o lugar implica pelo menos mais dois aspectos: a dependência do lugar (place dependece), que se refere às vantagens comparativas do lugar (o que tem ali que não tem em outros lugares); e a identidade com o lugar (place identity), que expressa as características do lugar com as quais a pessoa se identifica, vendo-se nele (HERNÁNDEZ et al., 2007; LEWICKA, 2008). Estes fatores operam como fundamentos da identidade territorial, ajudando a promover a fixação, sendo para isso o aspecto mais importante o envolvimento.

Kyle et al. (2004) afirmam que o attachment é baseado nos laços emocionais, na afetividade e na afetação que o lugar provoca na pessoa, sendo a base de todo o senso de lugar. Este laço de envolvimento foi chamado por Tuan (1980) de topofilia, referindo-se aos laços que ligam a pessoa a dada porção do espaço. Esta "filia" pode ou não ser buscada, assim como pode ou não ocorrer sem uma intencionalidade. Dessa forma, ela existe em relação tanto aos lugares do local de origem quanto aos do local de destino, estando no centro dos elementos que, do ponto de vista da experiência, irão influenciar na forma como os migrantes vão ou não se envolver com o novo lugar.

A relação ser-lugar pressupõe uma construção mútua e simultânea de ambos: o sujeito constrói o lugar e ao mesmo tempo é construído por esse (CASEY, 2001). Os lugares em que o indivíduo viveu ou vive são responsáveis pela constituição de sua maneira de ser, assim como garantem a continuidade desse ser, baseada na experiência. Por meio da percepção, sensação, cognição, representação e imaginação, o lugar-ser se constitui. A experiência tem como meio o corpo, grande mediador dessa relação (MERLEAU-PONTY, 1971). Segundo Casey (2001), o que o corpo experiencia tem efeito direto sobre ele mesmo. Digerida, a experiência passa a fazer parte integrante do corpo. Internalizada, ela é responsável, por meio do processo de somatização, pela forma de ser do sujeito. Com a internalização, o corpo incorpora o lugar que permanece na memória "in a virtual state" (CASEY, 2001, p.688) e se expressa na forma de ser do sujeito.

Nessas condições, a relação de somatização ser-lugar se estabelece quando há uma identificação entre eles. O indivíduo não pode ou não é capaz de ignorar toda sua história e formação, sendo indiferente às características de sua nova realidade 
para estabelecer prontamente relações com o local de destino. Não encontrando tal identificação de forma clara, o migrante tende a recriar seus lugares na expectativa de preservar sua forma de ser, bem como para reafirmar sua identidade territorial. São as relações e laços promotores do envolvimento com os lugares que dão as fundações e sustento para o ser (CASEY, 1993).

A necessidade por parte do migrante de preservar sua personalidade, sua identidade e voltar a ter a sensação do pertencimento leva a um gradual e contínuo processo de edificação de "lugares próprios", os quais permitem ao migrante enraizar-se. Estes lugares e suas articulações são, na verdade, o território dos migrantes. Esses lugares se configuram como base e fundamento das redes sociais estabelecidas por eles.

Entre os lugares dos quais o migrante tem que abrir mão na mudança, possivelmente sua maior perda é a casa. Lugar por excelência, onde estão fundadas as memórias e, em último grau, a própria identidade (BACHELARD, 1993), a casa é onde as sensações de pertencimento, conforto e segurança são máximas. A ligação entre o self e a casa é essencial na composição do mundo vivido e da própria inserção na sociedade (TUAN, 1982). A casa pode ser entendida como o lugar mais personificado do indivíduo, no qual cada detalhe é um reflexo das suas vontades e interesses. $O$ inverso também é verdadeiro, a casa como "fundamento espacial do ser-no-mundo" (MARANDOLA Jr., 2008b, p. 170) será o lugar mais absorvido e internalizado, sendo base constituinte da identidade e da forma de ser do indivíduo. A casa é onde a pessoa busca e funda seu lugar no mundo.

Tendo se afastado de sua referência identitária essencial, a casa, que pode envolver toda a terra natal e seu imaginário (BACHELARD, 1993; TUAN, 1980), o migrante precisa reconstruir sua casa ao mesmo tempo em que reconstitui a si mesmo. No ato/processo de personalizar a sua casa é que o migrante recoloca as bases espaciais de sua existência. Tornando a casa uma expressão de si mesmo, a pessoa traz à tona/convoca o ser. Personalizar a casa é apropriar-se, fixar-se, enraizar-se, sendo, portanto, fundamental para o migrante alcançar tranquilidade e estabilidade ontológica no lugar de destino.

A casa é o marco zero de todo o relacionamento espacial e social, servindo como ponto de apoio para que o migrante possa construir e interligar seus lugares. Nesse movimento de expansão, o migrante corrobora para o adensamento da rede social ao mesmo tempo em que tem a possibilidade de participar dela.

\section{Redes sociais: territórios e lugares migrantes}

Nesse processo de construção de seus lugares, o migrante vai compondo uma nova rede de relacionamentos baseada em lugares específicos, aumentando aos poucos sua sensação de segurança e promovendo seu enraizamento. Isso ocorre tanto com migrantes temporários (estudantes, trabalhadores que vão para outros países e deixam suas famílias no país de origem, etc.) quanto com famílias que migram para recomeçar a vida, embora com especificidades oriundas da própria característica do movimento e da sua situação.

A matriz desta nova rede, não raro, é a própria rede migratória que o levou até o local de destino. As chamadas redes sociais são fundamentais para compreender o processo migratório, tanto nos motivos e fluxos quanto para a discussão sobre a inserção do migrante no local de destino. Elas se configuram como uma das mais importantes estruturas para compreensão da organização social da migração (MASSEY et al., 1987). A análise estrutural das redes sociais da migração possibilita uma perspectiva complexa e instigante da organização social e cultural dos fluxos migratórios, integrando relações de parentesco, vizinhança e amizade (FAZITO, 2002).

Soares (2004) indica a proximidade da rede social com a rede pessoal e a própria rede migratória. Em todos os casos, pensar o papel das redes no fenômeno migratório permite entender a dimensão estrutural das escolhas e motivos da migração. Por outro lado, a partir das redes sociais, é possível compreender também o capital simbólico 
e material a que o migrante tem acesso no local de destino. É neste sentido que pensamos o papel da rede social e suas relações com a territorialidade e os lugares migrantes: em que medida elas conseguem diminuir o impacto da ruptura com o lugar de origem, em termos familiares, culturais e existenciais?

A inserção nas redes sociais possibilita a identificação e o pertencimento, podendo gerar alívio/amortecimento ao impacto das mudanças espaciais vividas pelos migrantes, por forneceram um espaço de segurança onde o seu modo de ser é reconhecido, ligando-o ao lugar-natal. Em vista disso, são importantes para amenizar os estresses causados pela migração (PASQUA; MOLIN, 2009).

A base da rede social é a cooperação entre seus integrantes, sendo que a identificação é o que fornece a liga e estabelece a confiança. Essas redes se fundamentam nas relações de amizade, vizinhança, parentesco, trabalho e origem comum (SOARES, 2002) entre os migrantes. A reciprocidade garante que a rede social funcione da maneira mais igualitária/democrática possível para seus membros, pois permite a troca do capital social entre os membros de forma geral. Fusco (2002) afirma ser a reciprocidade uma norma de comportamento no interior das redes sociais que funciona como um dos mecanismos da circulação do capital social.

Essas redes têm papel central no território dos migrantes. Nelas há o encontro das cosmovisões do migrante com o imaginário local, o que produz a recriação de símbolos que fazem parte da sua identidade, num verdadeiro encontro de culturas (SCALERA, 2009). As redes sociais representam, então, um suporte importante, uma vez que garantem o acomodamento/inserção do migrante, sendo constituídas tanto pelas pessoas e as relações que desenvolvem entre si como pelas organizações e instituições sociais (SOARES, 2002; 2004).

As redes sociais surgem no sentido de recuperar o bem-estar e o sentimento de pertencimento do migrante, constituindo uma resposta às dificuldades de inserção/ adaptação encontradas no local de destino. A cooperação para enfrentar os desafios impostos pela nova realidade vivida pelo migrante certamente traz mais benefícios do que ações individuais. As redes sociais funcionam para os migrantes como uma estratégia para sua sobrevivência e sustentabilidade (FAZITO, 2002).

Para o migrante, essas redes representam um referencial identitário e um meio fundamental para orientar seu envolvimento no local de destino. Em vez de partir de relações puras (GIDDENS, 2002), sem referenciais prévios, os migrantes possuem uma rede de lugares e relacionamentos baseados na confiança alicerçada na origem comum, sendo o fato de serem conterrâneos a base dos laços de confiança e do novo processo de territorialização. Seus lugares são construídos pelos e para os migrantes a partir de seus aspectos socioculturais. Os migrantes passam a adquirir domínio/ controle espacial do local de destino, gerando territorialidades ao recriar seu território identitário.

As redes sociais são, portanto, também redes territoriais, pois são alicerçadas em lugares específicos onde o grupo se encontra, conserva práticas comuns associadas ao lugar natal e propaga, a partir dele, sua territorialidade. Em geral, as redes sociais mantêm pouca relação com o sistema do lugar (GODOI, 1998), constituindo-se em lugares marginalizados ou pouco frequentados pelos estabelecidos, o que contribui para a separação entre estes e os migrantes. Não é muito diferente dos enclaves étnicos, em que códigos de conduta dos migrantes e estabelecidos constrangem o uso e a frequência de lugares na cidade, configurando territorialidades distintas entre os grupos (VARADY, 2005). Essa separação, no entanto, não é monolítica; há os lugares marcados pela permeabilidade entre os territórios e grupos, possibilitando o encontro e o compartilhamento do espaço.

Esta concentração nos territórios e lugares migrantes dificulta o estabelecimento de relações/interação com a cidade e seus habitantes, tornando difícil o desenvolvimento de laços afetivos com o local de destino, já que esse não é vivenciado livremente. A provável falta de familiaridade com as estruturas, dinâmica e cotidiano da cidade 
e também a prevalência da impessoalidade dificultam a constituição de lugares, pois seus dois "suportes" essenciais ficam ausentes: não há identificação com a cidade e/ou convívio com seus habitantes.

Esse é um fenômeno comum entre migrantes de baixa qualificação que migram clandestinamente para países centrais, como o caso de brasileiros nos Estados Unidos ou na Europa (SALES, 1999; ALMEIDA, 2009a; 2009b). Pela condição ilegal e dificuldades com a língua, os migrantes não se arriscam muito em viagens ou em transitar pelas cidades e raramente despendem seus dias ou horas de folga em atividades de lazer e convívio social, concentrando-se no trabaIho (em geral com longas jornadas) e nas remessas para suas famílias. Essa é outra forma de territorialidade e de envolvimento com o lugar de destino que tem sido analisada de diferentes maneiras, que tendem a ressaltar o impacto das novas possibilidades de mobilidade e de identidade na construção de territorialidades. Três abordagens ou entendimentos são mais presentes na leitura da migração e suas territorialidades contemporâneas: o transnacionalismo; a multiterritorialidade; e o entreterritórios.

O transnacionalismo, por exemplo, considera o movimento migratório para além de sua dinâmica polarizada e unidirecional, pois os fluxos não se limitam mais à saída do local de origem e ao assentamento (pensado como definitivo e determinante) no local de destino (MASSEY, 1993). A rigidez da permanência é posta em cheque pela intensa transitoriedade dos migrantes em função da interconectividade e expansividade de seus territórios e simultaneidade de práticas territoriais, culturais, econômicas e multinacionais (LINDÓN, 2007). O migrante mantém ativa e viva suas relações com lugares que estão geograficamente distantes, rompendo com a noção de obrigatoriedade da assimilação e aculturamento (vistos como processos indissociáveis da migração) (DUNN, 2008). Reconhecem-se a relevância e a potencialidade das práticas individuais e sociais do migrante que permitem a ele se adaptar sem transformações identitárias radicais. Isso abre a possibilidade da existência de identidades duais ou múltiplas (identificação não apenas com o lugar de origem, mas também com os lugares de destino) e de identidades unas (o indivíduo se identifica prioritariamente com seu lugar de origem).

Já a multiterritorialidade busca rever a forma como o processo de territorialização se apresenta na contemporaneidade (HAESBAERT, 2004; 2007). Num cenário mundial em que predominam a fluidez, o móvel e o globalizado, há o afrouxamento das fronteiras estatais e territoriais (que se tornam gradativamente mais permeáveis, embora mais conflituosas também) e os fluxos ocorrem de maneira mais aleatória, dispersa e descontinua, aumentando a tensão entre mobilidade e imobildiade. $\mathrm{O}$ migrante constrói múltiplas territorialidades, mas não apenas ele: todos vivemos vários territórios ao mesmo tempo. O território é produzido na articulação dos processos de desterritorialização e reterritorialização, que dão origem aos territórios-rede. Estes proporcionam a experiência, identificação e apropriação de diversos territórios e o trânsito em diversas territorialidades.

Por fim, a interterritorialidade propõe uma reflexão sobre a produção dos territórios pelos migrantes e suas implicações, num cenário de forte fluidez espaço-temporal, no qual se constroem territórios em movimento e sob múltiplas influências culturais (VANIER, 2008). Diante da intensificação da mobilidade em detrimento da estabilidade, há de se considerar que os processos de construção/estruturação territorial e formação da identidade do indivíduo migrante têm se tornado complexos. Os migrantes vivem entre territórios e entre culturas; desenvolvem uma identidade fragmentada em função de sua situação de ocupante da fronteira entre ser e não ser cidadão e de dividir-se entre estratégias de vida que atendam às exigências do local de origem e do local de destino (ALMEIDA, 2009c). Os migrantes ativam diversos territórios e todos eles contribuem para formação de sua identidade social e cultural; o cruzamento dessas pluralidades constitui a interterritorialidade.

As três perspectivas, aqui resumidas, possuem pontos em comum (especialmente seu ponto de partida: a fluidez contempo- 
rânea), mas dão soluções analíticas bem diferentes à situação das territorialidades no novo cenário das migrações deste século. Como abordagens e conceitos amplos, se prestam tanto às análises mais estruturais quanto às de trajetórias pessoais, o que nos permite uma ampla discussão sobre suas consequências.

Todas foram pensadas em termos da migração internacional, em que o controle legal do Estado-Nação exerce uma mediação essencial para todas estas teorias, pois não se pode esquecer que os vínculos com o país dependem também de ações e políticas específicas dos países de origem em amparar e promover a integração de seus cidadãos, que estão no exterior, à política e à vida cultural do país de origem (MENA, 2009). Além disso, situações de ilegalidade não permitem a comunicação ou a visita frequente entre parentes imigrados. Por outro lado, os países que têm grandes contingentes de cidadãos fora de suas fronteiras desenvolvem mecanismos de mantê-los ligados ao Estado-Nação. Até países como o Brasil, tradicionalmente receptor de migrantes, têm alterado sua postura em relação ao crescente número de emigrantes em diáspora, promovendo políticas transnacionais que visam manter estes brasileiros integrados. Redes de televisão internacionais têm tido um papel importante nesse sentido, assim como sistemas civis de registro e votação no exterior, facilitando a manutenção do vínculo com o país de origem e influenciando a formação das novas territorialidades no país de destino.

Do ponto de vista existencial, os migrantes constroem territorialidades próprias que são verdadeiros microcosmos ou pequenos mundos nos quais compartilham lugares, paisagens, signos e símbolos. Nos microcosmos tem-se uma existência espacial coletiva: o grupo pensa, organiza e vive seu território de maneira semelhante por partiIhar uma mesma cultura e um determinado estilo/modo de vida.

As redes sociais como uma rede de lugares-chave (lugares dos migrantes) podem ser entendidas como microcosmos ou microterritórios, resultantes de uma singularização, através de uma territorialização micro, na qual um grupo relacional exerce suas práticas sociais e afirma seus aspectos e atributos identitários, atendendo suas necessidades relacionais e preservando sua identidade (COSTA, 2005). Esta prática acaba sendo uma saída eficiente para a situação destes grupos migrantes.

O território ganha, assim, um desenho reticular, fundamentando e sustentando as redes sociais a partir de lugares hierarquizados conectados por uma rede de itinerários (BONNEMAISON, 2002). Esta forma de enraizamento coloca o lugar e o território como o principal ponto de suporte da identidade, estendendo a relação ser-lugar ao grupo-lugar.

A estruturação das redes sociais, portanto, é fundamental para a identidade territorial dos migrantes. Identificar-se com um território implica tornar-se parte de determinados círculos sociais e redes de lugares e itinerários e partilhar um sentimento coletivo em relação a signos, códigos e práticas culturais. No caso das migrações internacionais, associações de emigrantes formam e articulam muitas destas redes, funcionando como matricial da própria rede social (MELNIK et al., 2009; PADILLA, 2009). $\mathrm{Na}$ construção de suas redes, os migrantes exercem papel central como parte integrante e atuante na criação das geoestruturas, além de serem responsáveis por traçar na paisagem uma complexa semiografia capaz de exprimir e representar sua concepção de mundo.

Por sua fisionomia, dinâmica e ambiência, o lugar representa um ponto de familiaridade e receptividade para o migrante, onde se encarna sua cultura e se apresentam seus símbolos, signos e códigos. O lugar é por si só um referencial identitário, sendo a manifestação espacial dos laços de afetividade que ligam o grupo a seu território e fundam a identidade cultural (BONNEMAISON, 2002) e territorial.

Os migrantes tentam recriar, de certa forma, seu território perdido no novo lugar. Para fazê-lo, eles reproduzem os geossímbolos e a organização socioespacial de seu antigo território, além de garantirem lugares onde suas práticas possam ser realizadas. Ao restabelecer os elos espaciais e identitários, 
o grupo migrante é capaz de se enraizar e dar fundamento à sua identidade que, evidentemente, não será a mesma, pois agora são migrantes num outro lugar e não estão isentos das influências locais, incorporandoas mesmo que parcialmente. Recriar seu território é uma forma de dar suporte e manutenção à identidade e à sua forma de existir/ser pela presença de referenciais identitários. Nesse sentido, territorializar-se serve como um mecanismo protetor da segurança existencial (MARANDOLA Jr., 2008c).

Fundamentadas na família e nos laços elementares de parentesco, vizinhança e amizade, as redes sociais têm a capacidade de oferecer segurança existencial, atuando como casulo protetor (GIDDENS, 2002), o qual, constituído e construído pelos migrantes, filtra as eventuais ameaças que esses possam sofrer (MARANDOLA Jr., 2008b). A confluência de "lugares próprios" proporcionada pelas redes instiga as famílias, os amigos e conhecidos a se encontrarem e cultivarem seus laços, assim como estabelecerem novos outros.

O mesmo não pode ser dito com relação ao sistema do lugar, pois a falta de envolvimento entre os migrantes e a população local priva o casulo protetor de uma fonte importante de confiança e segurança, obrigando-o a estratégias de segurança desencaixadas, que estão diretamente vinculadas à existência de uma rede impessoal de instituições, organizações e empresas, cujo forte é a padronização e dispersão espacial. Paralela às redes sociais, uma nova rede organiza estes migrantes do tempo da globalização: a rede de lugares globais, chamada por Bauman (2001) de lugares neutros.

Segundo o autor, estes lugares envolvem certa homogeneização e padronização do comportamento social, não exigindo envolvimento ou socialização para serem frequentados; pelo contrário, isso é quase desnecessário. São os shoppings, as grandes redes de supermercados, lojas multinacionais e outros serviços similares que estão organizados segundo os mesmos códigos globais associados à vida metropolitana.

Esses lugares, ao contrário do sistema do lugar ou das redes sociais dos migrantes, são regidos por uma lógica desencaixada, que não exige conhecimento da cultura local para entender sua dinâmica. O migrante pode ir aos mesmos lugares padronizados que frequentava em sua terra natal e usufruir de uma impessoalidade que Ihe dá segurança. O migrante os frequenta sem inibição, pois não há o compromisso de se envolver com ele.

Essas características dos lugares neutros advêm, em grande medida, de sua relação com os sistemas abstratos, entre os quais estão os chamados sistemas peritos (GIDDENS, 1991).

Esses sistemas tendem a apresentar certa uniformidade em termos de funcionamento, independentemente de sua localidade. Seu funcionamento baseia-se em alguns procedimentos padrão que, ao serem cumpridos, permitem sua utilização. Os sistemas peritos são os principais responsáveis pelas transformações ocorridas nas relações pessoais, sendo grandes promotores da impessoalidade.

A possibilidade de trafegar entre diferentes lugares, independentemente de seus atributos socioespaciais e socioculturais, tem permitido o deslocamento dos indivíduos de forma muito mais fluida, fora das suas territorialidades. Um processo cada vez mais frequente que tem marcado nossas metrópoles corresponde às migrações espontâneas, marcadas por decisões individuais (MARANDOLA Jr., 2008b,c). Em vez de grupos sociais migrantes, ligados a um lugar específico que operava como lugar de expulsão, hoje temos migrantes de grupos difusos espacialmente, que, no espaço impessoal da metrópole, não têm se orientado unicamente pela existência de redes sociais previamente estabelecidas.

Torna-se possível viver uma vida inteira numa cidade ou região sem integrar-se às dinâmicas do sistema do lugar. Mesmo após vários anos, a pessoa ainda pode se considerar "de fora", pois os laços de envolvimento com o lugar não ultrapassam aqueles ligados à sobrevivência e às práticas cotidianas funcionais. Este tipo de experiência é possível tanto pelos lugares neutros quanto pela possibilidade de manter os laços essenciais com o lugar de origem, o que tem acontecido tanto internamente quanto 
internacionalmente (BAUMAN, 2007). Os lugares neutros facilitam a adaptação na medida em que não exigem familiaridade e envolvimento com o lugar (MARANDOLA Jr., 2008b).

Por outro lado, se antes mudar-se significava distanciamento absoluto, hoje migrantes regionais ou até internacionais conseguem manter vívidos os laços com a terra natal, ficando, em muitos casos, integrado existencialmente a ele e apenas funcionalmente ligados ao lugar de moradia atual. As melhorias tanto nos sistemas de transporte (malhas aérea e rodoviária) quanto de comunicação (telefonia e Internet) possibilitam esta vivência deslocada do lugar: à distância.

O reflexo disso, no entanto, é que as regiões metropolitanas estão cheias de migrantes temporários: pessoas que vivem a semana no trabalho e acorrem à casanatal no final de semana, feriados e férias. Pessoas que, ao se aposentarem, voltarão para seus lugares e territórios que foram mantidos durante anos. São temporários por não considerarem este o seu lugar; entendem-se fora do lugar (MARTINS, 1986).

Estes migrantes aproveitam a possibilidade do deslocamento e da proximidade para manter seus laços fundamentais, seu casulo protetor (GIDDENS, 2002) fundado em sua casa e terra natal. Assim, tendem a ter relações mais funcionais com a cidade e a região, morando nela durante a semana, mas, em função de seus retornos periódicos, mantêm seus laços mais fundamentais e duradouros com sua cidade natal. Atividades corriqueiras, que exigem confiança e conhecimento locais, como comprar bens duráveis (um carro, por exemplo), tratamentos de saúde mais delicados, planejamento de viagens, etc., não são realizadas na metrópole, mas sim na terra natal, onde as redes e a memória dão segurança, além de ser uma estratégia de manter o vínculo (MARANDOLA Jr., 2008b, c).

As metrópoles, em especial em áreas muito densas e com alta fluidez, abrigam cada vez mais pessoas que não procuram e até evitam o envolvimento com ela: não querem pertencer, seu lugar é outro. Quais são as consequências?
Para a cidade, diminuem a participação e o envolvimento com seus próprios problemas. Reduzir a cidade à sua dimensão funcional potencializa que ela seja guiada pelo consumo e pelos sistemas produtivos. Isso retroalimenta a disposição das pessoas de não fazerem da metrópole seu lugar. Para as pessoas, seu não envolvimento as mantém fora de redes de proteção locais, estando completamente dependentes das redes privadas de proteção, produzindo uma separação clara entre migrantes com e sem condições de pagar por estes mecanismos.

A indiferença torna-se uma forma de relação com o lugar, estando associada diretamente ao não envolvimento que, para Tuan (1998), é uma forma de escapismo que pode afetar de forma ambivalente a vulnerabilidade individual do escapista: expondo-o a certos riscos, protegendo-o de outros. A coletividade, no entanto, será atingida de forma mais direta, afetando diretamente a vulnerabilidade do lugar e a efetividade das redes sociais de prover proteção.

\section{Migração em tempos líquidos}

É fundamental pensar os movimentos migratórios para além das condições ou motivações econômicas. Enquanto deslocamento de pessoas, a intencionalidade e a volição têm papel central em vários momentos do processo. Não que hoje não vejamos grupos sociais em migração. Os fluxos continuam sendo parte fundamental da problemática. No entanto, a importância de questões existenciais aumenta nos atuais tempos líquidos da modernidade líquida, tempo de flexibilização de todos os campos da vida social, inclusive das relações amorosas, da vida comunitária, das instituições e das normatizações (BAUMAN, 2001; 2007). Nessa fluidez contemporânea, o peso das decisões tem sido jogado para o indivíduo, mesmo que não haja parâmetros socialmente definidos que o oriente em sua decisão (BECK, 1999). A dimensão geográfica do processo, ligada à constituição das identidades territoriais, do lugar e das redes sociais é fundamental para compreender este ser migrante e os riscos e incertezas aos quais fica exposto. 
Mobilidade é parte integrante de nosso tempo. A sociedade se volta para os móveis, criticando os imóveis. Essa constante mobilidade gera incertezas, tornando as balizas existenciais fluídas e frouxas (BAUMAN, 2007; GIDDENS, 2002). Se vivemos realmente num momento em que a mobilidade tornou-se um paradigma para as ciências sociais, ou seja, um fundamento da própria reprodução social, como o quer Urry (2007), a reflexão sobre a migração tem que avançar na mesma medida, incorporando as mais diferentes dimensões e consequências relacionadas ao fenômeno. Hoje, a migração possui muito mais facetas do que as condicionantes externas ou estruturais. Em vista disso, é essencial questionar quais são as consequências espaciais e existenciais do ato de migrar. Ao mesmo tempo, as tradicionais variáveis demográficas (ciclo vital, gênero e origem) são reveladoras das implicações para os lugares de origem e destino, abrindo uma caixa-preta que precisa ser desvelada.

As fronteiras são construídas por corporeidades, enquanto os valores mantêm uma tendência mundializada de difusão. Comunidades são instituídas e vividas corporeamente, sendo a base do engajamento e do próprio sentido de identidade (AHMED, 1999). As trajetórias ganham peso num contexto em que a estrutura do sistema criou possibilidades de escolha (via mercado) de estilos de vida, direções, destinos, motivações (VELDE; NAERSSEN, 2007; ASCHER, 1995). Os fluxos clássicos continuam a existir, mas há muitos outros que são orientados por lógicas distintas, produzindo consequências específicas tanto para os locais de destino quanto para os de origem.

Em vista disso, é importante pensar tanto os móveis quanto os imóveis (BILSBORROW, et al., 1984; HAESBAERT, 2008). Por que foi e por que ficou? Estamos em uma transição de valores entre a virtude de ser imóvel (fixado, apegado às raízes, tradicional) e ser móvel (desembaraçado, progressista, moderno) (CRESSWELL, 2006). Mas o que não se fala são dos riscos desta mobilidade e do potencial desagrega- dor para a personalidade e a autoidentidade (SENNET, 2005).

Há cada vez mais migrantes sem redes que estão jogados no espaço metropolitanoglobalizado, territorializando-se nos lugares neutros, os quais garantem melhor adaptação a cada mudança. As redes sociais começam a se estabelecer a partir de relações puras (GIDDENS, 2002), diminuindo ou até perdendo sua efetiva força territorializadora. No entanto, quais são as consequências de longo prazo deste tipo de identidade territorial? Seria esta substituta daquela ligada à casa-natal e ao casulo protetor? Quem está mais exposto a riscos: o migrante metropolitano, que em todo lugar está em sua rede de lugares, ou aquele menos móvel, que se fixa fortemente em seu sistema do lugar?

Esta fluidez tem sido tratada de diferentes maneiras: multiterritorialidade, interterritorialidade, transnacionalismo. O que estas abordagens têm em comum é a constatação de que há necessidade de compreendermos as formas de identidade e territorialização na sociedade contemporânea, que estão em mutação e não são tão claras quanto no estágio anterior da modernidade.

Nossos territórios hoje são construídos de muitas maneiras: na fixidez, no movimento, na continuidade, na descontinuidade e em arranjos com escalas espaço-temporais muito variadas. Identidade, alteridade, temporalidade são temas inerentes à questão do território e das territorialidades atualmente, sendo fundamentais para todo processo migratório contemporâneo (CLAVAL, 1999). Além disso, estamos constantemente envolvidos em várias territorialidades diferentes, difusas e mutantes. A questão que nos interessa, pensando nas implicações existenciais e territoriais da migração, é: quais são as consequências desta forma de serno-mundo para a constituição do ser-lugar?

Para caminhar em direção à compreensão do que é ser migrante, é fundamental entender estes novos processos de territorialização e de construção de significados. Se os referenciais identitários se dispersam no espaço, as possibilidades podem ser muito maiores de identificação, culminando numa territorialidade ampla e dispersa. Mas a distância não é exercida sem cobrar seu 
preço. Os riscos dessas novas formas de constituição das identidades atingem diretamente o ser, produzindo consequências existenciais significativas (MARANDOLA Jr., 2008a). Bauman (2007) fala de tremores existenciais que atingem os mecanismos de autoidentidade e que fluidificam as certezas. A incerteza, uma marca de qualquer vida migrante, é a marca de nossa época, e por isso ser migrante é a experiência de nosso tempo.

É necessário, igualmente, refletir sobre a multiplicidade de modalidades e processos migratórios. Uma constelação de motivos, densidades, direções, temporalidades e espacialidades configura as migrações e as mobilidades contemporâneas, tornando necessário um esforço interdisciplinar para acompanhar estas mutações. Por outro lado, as diferentes situações espaciais também precisam ser consideradas. Migrantes em espaços urbanos metropolitanos ou em pequenas cidades e áreas rurais enfrentarão condições e desafios diferenciados, relacionados com a inserção destes lugares nas redes, bem como com a própria especificidade das dinâmicas sociais locais.

Os processos associados a territorialização, desterritorialização e reterritorialização têm sido apontados como essenciais para compreender estas dinâmicas atualmente. No entanto, é necessário prestar atenção à tendência de positivar estes movimentos

\section{Referências}

AHMED, S. Home and away: narratives of migration and estrangement. International Journal of Cultural Studies, v. 2, n. 3, p. 329-347, 1999.

ALMEIDA, M. G. As ambiguidades do ser exmigrante: o retorno e o viver entre territórios. In: ALMEIDA, M. G. (Org.). Territorialidades na América Latina. Goiânia: UFG, 2009a, p. 208-218.

O sonho da conquista do Velho Mundo: a experiência de imigrantes brasileiros no viver entre territórios. In: ALMEIDA, M. G.; NATES CRUZ, B. (Orgs.). Território e cultura: inclusão e exclusão nas dinâmi- como sequenciais ou ordenados, ou mesmo à ainda prevalência na leitura puramente materialista do território e da territorialidade (SAHR; SAHR, 2009). A fluidez está nos movimentos, nos sentidos e na própria constituição territorial e do ser, e por isso o pensar estes fenômenos deve ser no mesmo sentido. A dimensão ontológica da migração precisa ser investigada em suas implicações territoriais, contribuindo assim para uma perspectiva abrangente e compreensiva da migração e da mobilidade.

Para isso, se mostra necessário avançar nas metodologias qualitativas, como as biografias e a análise das especificidades e da diversidade (LECHNER, 2007). Com a fluidez contemporânea, métodos que dão relevo às trajetórias particulares permitem apreender novos elementos que são relevantes no processo, ampliando assim o universo de questões e fatores relevantes no fenômeno da migração.

O desafio que se apresenta aos estudos migratórios é avançar teoricamente em suas abordagens, buscando uma compreensão abrangente e multifacetada do fenômeno. As dimensões territorial e existencial da migração fazem parte constituinte do fenômeno, e por isso sua reflexão e o avanço na sua problematização contribuirão para enfrentar as questões que a sociedade tem colocado sobre a mobilidade no mundo contemporâneo.

cas socioespaciais. Goiânia: UFG, 2009b, p. 163-174.

Diáspora: viver entre-territórios.

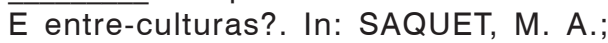
SPOSITO, E. S. (Orgs.). Territórios e territorialidades: teorias, processos e conflitos. São Paulo: Expressão Popular, 2009c, p. 175-195.

ASCHER, F. Métapolis: ou l'avenir dês villes. Paris: Odile Jacob, 1995.

BACHELARD, G. A poética do espaço. Trad. Antonio de P. Danesi. São Paulo: Martins Fontes, 1993. 
BADIE, B. O fim dos territórios. Lisboa: Instituto Piaget, 1996.

BAUMAN, Z. O mal-estar da pós-modernidade. Rio de Janeiro: Jorge Zahar, 1998.

Modernidade líquida. Rio de Janeiro: Jorge Zahar, 2001.

. Tempos líquidos. Trad. Carlos A. Medeiros. Rio de Janeiro: Jorge Zahar, 2007.

BECK, U. World risk society. Cambridge: Blackwell, 1999.

BERRY, J.; POORTINGA, Y. Cultural psychology: research and applications. Cambridge: The Cambridge University Press, 2002.

BILSBORROW, R. E.; OBERAI, A. S.; STANDING, G. Migration surveys in low income countries: guidelines for survey and questionnaire design. London: Croom Helm, 1984.

BOLLNOW, O. F. O homem e o espaço. Trad. Aloísio Leoni Schmid. Curitiba: Ed. UFPR, 2008.

BONNEMAISON, J. Viagem em torno do território. In: CORRÊA, R. L.; ROSENDHAL, Z. (Orgs.). Geografia cultural: um século (3). Rio de Janeiro: EdUERJ, 2002, p. 83-131.

Culture and space: conceiving a new cultural geography. Trad. Josée PénotDemetry. London: I.B. Tauris, 2005.

BONNEMAISON, J.; CAMBRÉZY, L. Le lien territorial. Géographie et Cultures, n.20, p.7-18, 1996.

BRETELL, C. B.; HOLLIFIELD, J. F. Migration theory: taking across disciplines. In: BRETELL, C. B.; HOLLIFIELD, J. F. (Eds.). Migration theory: taking across disciplines. London: Routledge, 2008, p. 1-29.

CASEY, E. S. Getting back into place: toward a renewed understanding of the place-world (studies in continental thought). Indiana: Indiana University Press, 1993.

Between geography and philosophy: what does it mean to be in the place-world? Annals of the Association of American Geographers, v. 91, n. 4, 2001, p. 683-693.
CLAVAL, P. O território na transição da pósmodernidade. GEOgraphia, ano I, n. 2, p. 7-26, 1999.

COSTA, B. P. As relações entre os conceitos de território, identidade e cultura no espaço urbano: por uma abordagem microgeográfica. In: CORRÊA, R. L.; ROSENDAHL, Z. (Orgs.). Geografia: temas sobre cultura e espaço. Rio de Janeiro: EdUERJ, 2005, p. $79-113$.

CRESSWELL, T. On the move: mobility in the modern western world. New York: Routledge, 2006.

DeBIAGGI, S. D.; PAIVA, G. J. (Orgs.). Psicologia, e/imigração e cultura. São Paulo: Casa do Psicólogo, 2004.

DINER, H. R. History and the study of immigration. In: BRETELL, C. B.; HOLLIFIELD, J. F. (Eds.). Migration theory: taking across disciplines. London: Routledge, 2008, p. 31-62.

DUNN, K. Guest editorial-comparative analyses of transnationalism: a geographic contribution to the field. Australian Geographer, v. 39, n. 1, p. 1-7, 2008.

ELIAS, N. A sociedade dos indivíduos. Trad. Vera Ribeiro. Rio de Janeiro: Jorge Zahar, 1994.

FAZITO, D. A análise de redes sociais (ARS) e a migração: mito e realidade. In: ENCONTRO DA ASSOCIAÇÃO BRASILEIRA DE ESTUDOS POPULACIONAIS, 13, 2002, Ouro Preto. Anais... Campinas: Abep, 2002.

FAVELL, A. Rebooting migration theory: interdisciplinarity, globality, and postdisciplinarity in migration studies. In: BRETELL, C. B.; HOLLIFIELD, J. F. (Eds.). Migration theory: talking across disciplines. London: Routledge, 2008, p. 259-278.

FUKS, B. F. Psicanálise, exílio e estrangeiro: uma versão sobre origem e transmissão da descoberta freudiana. In: POVOA NETO, H.; FERREIRA, A. P. (Orgs.). Cruzando fronteiras disciplinares: um panorama dos estudos migratórios. Rio de Janeiro: Revan, 2005, p. 183-197.

FUSCO, W. Conexão origem-destino: migrantes brasileiros no exterior. In: EN- 
CONTRO DA ASSOCIAÇÃO BRASILEIRA DE ESTUDOS POPULACIONAIS, 15, 2006, Caxambu. Anais... Campinas: Abep, 2002.

GIDDENS, A. As conseqüências da modernidade. São Paulo: Ed. Unesp, 1991.

Modernidade e identidade. Trad. Raul Fiker. São Paulo: Ed. Unesp, 2002.

GODOI, E. P. de. O sistema do lugar: história, território e memória no sertão. In: NIEMEYER, A. M. de; GODOI, E. P. de (Orgs.). Além dos territórios: para um diálogo entre a etnologia indígena, os estudos rurais e os estudos urbanos. Campinas: Mercado das Letras, 1998, p. 97-131.

GOFFMAN, E. Estigma: notas sobre a manipulação da identidade deteriorada. 4 ed. Rio de Janeiro: Zahar, 1982.

HAESBAERT, R. O mito da desterritorialização: do "fim dos territórios" à multiterritorialidade. Rio de Janeiro: Bertrand Brasil, 2004.

Identidades territoriais: entre a multiterritorialidade e a reclusão territorial (ou: do hibridismo cultural à essencialização das identidades). In: ARAUJO, F. G. B. A.; HAESBAERT, R. (Orgs.). Identidades e territórios: questões e olhares contemporâneos. Rio de Janeiro: Access, 2007, p. 33-56

. Hibridismo, mobilidade e multiterritorialidade numa perspectiva geográficocultural integradora. In: SERPA, A. (Org.). Espaços culturais: vivências, imaginações e representações. Salvador: Edufba, 2008, p. 393-419.

HALL, S. A identidade cultural na pós-modernidade. Trad. Tomáz T. Silva e Guacira L. Louro. Rio de Janeiro: DP \&A, 2003.

Da diáspora: identidades e mediações culturais. Belo Horizonte: Ed. UFMG, 2009.

HARDWICK, S. W. Place, space, and pattern: geographical theories in international migration. In: BRETELL, C. B.; HOLLIFIELD, J. F. (Eds.). Migration theory: taking across disciplines. London: Routledge, 2008, p. 161-182.

HEIDEGGER, M. Construir, habitar, pensar. In: HEIDEGGER, M. Ensaios e conferências.
Trad. Emmanuel C. Leão; Gilvan Fogel; Marcia S. C. Schuback. Petrópolis: Vozes, 2001a, p. 125-141.

Ciência e pensamento do sentido. In: HEIDEGGER, M. Ensaios e conferências. Trad. Emamanuel C. Leão. Petrópolis: Vozes, 2001b, p. 39-60.

HERNÁNDEZ, B. et al. Place attachment and place identity in natives and non-natives. Journal of Environmental Psychology, n.27, p. 310-319, 2007.

HOGAN, D. Internal migration, access to information, and the use of urban resources in São Paulo. Tese (Doutorado em Sociologia) - Cornell University, Estados Unidos, 1974.

KELLERMAN, A. Personal mobilities. London: Routledge, 2006.

KYLE, G. et al. Effects of place attachment on user's perception of social and environmental conditions in a natural setting. Journal of Environmental Psychology, n. 24, p. 213-225, 2004.

LECHNER, E. Imigração e saúde mental. Migrações, n. 1, p. 79-101, set. 2007.

LEWICKA, M. Place attachment, place identity, and place memory: restoring the forgotten city past. Journal of Environmental Psychology, n. 28, p. 209-231, 2008.

LINDÓN, A. Espacialidades, desplazamientos y transnacionalismo. Papeles de Población, Toluca, v. 13, n. 53, p. 71-101, 2007.

LOW, S. M.; ALTMAN, I. Place attachment: a conceptual inquiry. In: ALTMAN, I.; LOW, S. M. (Eds.). Place attachment. New York: Plenum Press, 1992, p. 1-12.

LUSSI, C.; MARINUCI, R. Vulnerabilidade social em contexto migratório. Centro Scalabriniano de Estudos Migratórios, 2007. Disponível em: <http://www.csem.org.br/ pdfs/vulnerabilidades_dos_migrantes.pdf $>$.

LUSSI, C. Conflitos e vulnerabilidades no processo migratório. Centro Scalabriniano de Estudos Migratórios, 2009. Disponível em: <http://www.csem.org.br/2009/conflitos_e_ vulnerabilidades_no_processo_migratorio. pdf $>$. 
MALPAS, J. Heidegger's topology: being, place, world. Cambridge: MIT Press, 2008.

MARANDOLA Jr., E. Insegurança existencial e vulnerabilidade no habitar metropolitano. Caderno de Geografia, Belo Horizonte, v. 18, n. 29 , p. $39-58,2008$.

. Entre muros e rodovias: os riscos do espaço e do lugar. Antropolítica, Niterói, v. 23 , p. $195-217,2008 b$.

Habitar em risco: mobilidade e vulnerabilidade na experiência metropolitana. Tese (Doutorado em Geografia) - Instituto de Geociências, Universidade Estadual de Campinas, Campinas, 2008c.

MARTINS, J. de S. O vôo das andorinhas: migrações temporárias no Brasil. In: Não há terra para plantar neste verão. Petrópolis: Vozes, 1986.

MASSEY, D. Pelo espaço: uma nova política da espacialidade. Trad. Rogério Haesbaert. Rio de Janeiro: Bertrand Brasil, 2008.

MASSEY, D. et al. Return to Aztlan: the social process of international migration from Western Mexico. Berkeley: University of California Press, 1987.

Theories of international migration: a review and appraisal. Population and Development Review, v. 1, n. 1, p. 411-466, set. 1993.

MELNIK, M. et al. Mediating integration: latino immigrant organizations in greater Boston. Revista Interdisciplinar da Mobilidade Humana, Ano XVII, n. 32, p. 61-78, jul./dez. 2009.

MENA, N. M. As respostas extra-territoriais dos Estados latino-americanos face à migração transnacional. Migrações, Lisboa, n. 5, p. 37-52, out. 2009.

MERLEAU-PONTY, M. Fenomenologia da percepção. Trad. Reginaldo di Piero. Rio de Janeiro: Freitas Bastos, 1971.

MESQUITA, Z. Do território à consciência territorial. In: MESQUITA, Z.; BRANDÃO, C. R. (Orgs.). Territórios do cotidiano: uma introdução a novos olhares e experiências. Porto Alegre: Ed. da Universidade, 1995, p. 76-92.
OLIVEIRA, P. R. M. O migrante, seu drama psíquico e a recepção das diferenças. In: POVOA NETO, H.; FERREIRA, A. P. (Orgs.). Cruzando fronteiras disciplinares: um panorama dos estudos migratórios. Rio de Janeiro: Revan, 2005, p. 163-174.

PADILLA, B. et al. Portugueses gaúchos: socio-political transnationalism, integration and identities in the River Plate Region. Migrações, Lisboa, n. 5, p. 185-201, out. 2009.

PASQUA, L. D.; MOLIN, F. Algumas considerações sobre as consequências sociais e psicológicas do processo migratório. Revista Interdisciplinar da Mobilidade Humana, Ano XVII, n. 32, p. 101-116, jul./dez. 2009.

RAFFESTIN, C. Immagi e identità territoriali. In: DEMATTEIS, G.; FERLAINO, F. (Eds.). II mondo e I luoghi: geografie delle identità e del cambiamento. Torino: IRES, 2003, p. 3-11.

A produção das estruturas territoriais e sua representação. In: SAQUET, M. A.; SPOSITO, E. S. (Orgs.). Territórios e territorialidades: teorias, processos e conflitos. São Paulo: Expressão Popular, 2009, p. 17-35.

RAVENSTEIN, E. G. As leis da migração. In: MOURA, H. A. (Org.). Migração interna, textos selecionados: teorias e modelos de análise. Fortaleza: BNB, 1980, p. 19-88.

SACK, R. D. Homo geographicus. Baltimore: Johns Hopkins University Press, 1997.

SAHR, C. L. L.; SAHR, W.-D. Territórios - faxinais - espaços. A problemática "espaço/ território" na formação social brasileira. In: SAQUET, M. A.; SPOSITO, E. S. (Orgs.). Territórios e territorialidades: teorias, processos e conflitos. São Paulo: Expressão Popular, 2009, p. 143-173.

SALES, T. Brasileiros longe de casa. São Paulo: Cortez, 1999.

SANTOS, B. S. A crítica da razão indolente. São Paulo: Cortez, 2000.

SAQUET, M. A. Abordagens e concepções de território. São Paulo: Expressão Popular, 2007. 
Por uma abordagem territorial. In: SAQUET, M. A.; SPOSITO, E. S. (orgs.). Territórios e territorialidades: teorias, processos e conflitos. São Paulo: Expressão Popular, 2009, p. 73-94.

SARAMAGO, L. A topologia do ser: lugar, espaço e linguagem no pensamento de Martin Heidegger. Rio de Janeiro: Ed. PUCRio; Loyola, 2008.

SCALERA, D. Incontro tra le cuolture. Le reti migratoire. Revista Interdisciplinar da Mobilidade Humana, Ano XVII, n. 32, p. 117-132, jul./dez. 2009.

SENNETT, R. A corrosão do caráter: conseqüências pessoais do trabalho no novo capitalismo. Trad. Marcos Santarrita. 9 ed. Rio de Janeiro: Record, 2005.

SIMMEL, G. O estrangeiro. In: MORAES FILHO, E. (Org.). George Simmel: sociologia. São Paulo: Ática, 1983.

. Bridge and door. Theory, Culture

\& Society, v. 11, n. 1, p. 5-10, 1994.

SINGER, P. Economia política da urbanização. São Paulo: Brasiliense, 1973.

SOARES, W. Para além da concepção metafórica de redes sociais: fundamentos teóricos da circulação topológica da migração internacional. In: ENCONTRO DA ASSOCIAÇÃO BRASILEIRA DE ESTUDOS POPULACIONAIS, 13, Ouro Preto, 2002. Anais... Campinas: Abep, 2002.
Análise de redes sociais e os fundamentos teóricos da migração internacional. Revista Brasileira de Estudos de População, v. 21, n. 1, p. 101-116, jan./ jun. 2004.

TUAN, Y.-F. Topofilia: um estudo da percepção, atitudes e valores do meio ambiente. Trad. Lívia de Oliveira. São Paulo: Difel, 1980.

Segmented worlds and self: group life and individual consciousness. Minneapolis: University of Minnesota Press, 1982.

Escapism. Baltimore: Johns Hopkins University Press, 1998.

URRY, J. Mobilities. London: Polity, 2007.

VANIER, M. Les pouvoir des territories: essai sur l'interterritorialité. Paris: Econômica, 2008.

VARADY, D. P. (Ed.). Desegregating the city: ghettos, enclaves, \& inequality. Albany: State University of New York Press, 2005.

VELDE, M.; NAERSSEN, T. People, borders and trajectories: a model to approach migration in the enlarged European Union. In: NAERSSEN, T.; VELDE, M. (Eds.). Migration in a new Europe: people, borders and trajectories. Rome: Società Geografica Italiana, 2007, p. 145-154.

VIANA, W. Síndrome de migração: fundamentos psicanalíticos sociológicos e terapêuticos. Campinas: Iprosam, 1978.

\section{Resumen}

Ser emigrante: implicaciones territoriales y existenciales de la emigración

Migración y movilidad son fenómenos constituyentes de la experiencia contemporánea. Estar en el mundo, hoy, es convivir con la movilidad y la migración, y todas sus implicaciones. Desde el punto de vista existencial, esta es una experiencia desconcertante, en la que las referencias espaciales y socioculturales son reconstituidas, en un proceso que involucra y alcanza la propia esencia de la autoidentidad: la seguridad existencial. Partimos de la pregunta "ique es ser emigrante?", con el objeto de reflexionar sobre las implicaciones existenciales y territoriales de la emigración, procurando entenderla como fenómeno vivido en diferentes escalas espacio-temporales, aunque posee, desde el punto de vista fenomenológico, una misma esencia constitutiva. Este recorrido lleva a un pensamiento ontológico acerca de las estrategias y consecuencias del fenómeno migratorio, lo que propicia la reflexión sobre el papel 
de la identidad territorial, de la implicación con el lugar y de las redes sociales en el proceso de salir del lugar de origen y establecerse en un nuevo lugar de destino.

Palabras-clave: Movilidad. Lugar. Seguridad existencial. Fenomenología de la emigración. Geografía de la población.

\section{Abstract}

Being a migrant: territorial and existential implications of migration

Migration and mobility are determining phenomena of contemporary experience. Living in today's world means having to deal with mobility and migration, with all the implications this process involves. From an existential point of view, migration is a disconcerting experience where spatial and sociocultural references must be reconstituted in a process that shakes up the core of an individual's personal identity, namely, his or her existential security. We start off here with the question of "What is it to be a migrant?" From there, we discuss the existential and territorial implications of migration and look at it as a phenomenon that is experienced on different spatial and temporal scales. Phenomenologically, this experience has a single constitutive essence that leads to an ontological way of thinking about the strategies and consequences of the phenomenon of migration. This, in turn, leads to a reflection on the role of territorial identity and on involvement with places and social networks when a person leaves her or his place of origin and settles down somewhere else, that becomes their place of destination.

Keywords: Mobility. Place. Existential security. Phenomenology of migration. Population geography.

Recebido para publicação em 01/05/2010

Aceito para publicação em 15/06/2010 